\title{
INDÍCIOS DE Rotavirus NA ETIOLOGIA DE UM SURTO DE INFECÇÃO DE ORIGEM ALIMENTAR ${ }^{1}$
}

\author{
Maura Menezes RODRIGUES ${ }^{3}$, Brigitte Marie Angele BERTIN², Luana de ASSIS²,
}

Edelmiro Balado DUARTE ${ }^{2}$, Angela Maria Oliveira de $\mathrm{AVELAR}^{2}$, Joana Terra Seca da PAIXÃO²,

\author{
Mariana da Costa MATTOS², Miliane Moreira Soares de SOUZA ${ }^{3, *}$
}

\section{RESUMO}

Doenças transmitidas por alimentos têm merecido especial atenção por parte de pesquisadores em todo mundo. Os surtos alimentares de etiologia viral têm sido tratados inadequadamente como sendo de menor importância quando comparados com aqueles de etiologia bacteriana. O rotavírus é um importante agente causador de doenças diarréicas graves, sendo responsável por significativo número de óbito em vários países. Este trabalho é um relato de surto de gastroenterite ocasionado por rotavírus, ocorrido em estabelecimento comercial com 720 funcionários, dos quais 51 relataram sintomas de mal-estar, vômito, diarréia, náusea e calafrios. Foi realizada análise microbiológica da água, coletada em diversos pontos, bem como de todos os alimentos e bebidas oferecidos para consumo dos funcionários. Nenhum destes apresentou contaminação por microbiota bacteriana patogênica, nem alterações em suas características sensoriais e organolépticas. De acordo com a estimativa do risco atribuível a cada um dos alimentos, o pão com manteiga oferecido foi apontado como alimento suspeito, somado ao fato de que o único manipulador incumbido do preparo deste produto apresentava-se com infecção por rotavirus.

Palavras-chave: rotavírus; infecção alimentar; surto.

\section{SUMMARY}

ROTAVIRUS AS POTENTIAL ETHIOLOGICAL AGENT OF A FOODBORNE DISEASE OUTBREAK. Foodborne diseases have been deserving special attention by researchers of the whole world. Viral etiology outbreaks of foodborne diseases have been improperly treated as less important than bacterial ones. Rotavirus is the most reported cause of gastroenteritis and accounts for thousands of deaths annually. The present work reports a Rotavirus-induced disease outbreak in a commercial establishment, where 51 employees related symptoms like diarrhea, vomits, nausea. Water, food and beverages were analyzed microbiologically. No pathogenical bacterial contamination were detected, neither any modification on sensorial characteristics. According to the "attributable risk" of each food involved, bread and butter was considered suspicious food, and epidemiological approach pointed to the fact that the employee responsible for preparing this food was rotaviruses sicked just before the outbreak spreading.

Keywords: rotavirus; foodborne diseases; outbreak.

\section{1 - INTRODUÇÃO}

Nos últimos anos, tem-se mostrado cada vez mais comum, em vários países, casos de doenças veiculadas por alimentos, de etiologias variadas, muitas vezes por contaminação da matéria prima ou do produto pronto para consumo [8]. Na maioria das vezes, casos de infecções alimentares estão relacionadas ao consumo de alimentos que sofrem manipulação exacerbada associada as más condições de armazenamento e acondicionamento, permitindo a exposição direta ao ambiente, propiciando a contaminação e posterior veiculação de agentes de natureza infecciosa aos consumidores $[3,4,5,6,18$, 26]. Os microrganismos representam uma ameaça à segurança dos alimentos, podendo ser causadores de doenças de origem alimentar. Entre estes, existem vírus responsáveis por várias dessas enfermidades, tais como o vírus da Hepatite A, o vírus de Norwalk e o Rotavírus. Os sintomas de infecção causada por Rotavirus caracterizam-se por gastroenterite, com vômito e diarréia, dor

\footnotetext{
1. Recebido para publicação em 17/10/2002. Aceito para publicação em 03/10/2003 (001002).

2. Bioqualitas Análises de Alimentos e Treinamentos Contínuos Ltda. Instituto de Veterinária, Departamento de Microbiologia e Imunologia Veterinária, Universidade Federal Rural do Rio de Janeiro. CEP:23835-520, Seropédica, RJ, Brasil.E-mail: miliane@ufrrj.br

${ }^{3}$ Curso de Pós-Graduação em Microbiologia Veterinária, Universidade Federal Rural do Rio de Janeiro.

*A quem a correspondência deve ser enviada.
}

abdominal, podendo ocorrer febre branda. Em geral, seu período de incubação é de 1 a 3 dias, podendo os sintomas perdurar por 4 a 8 dias [14]. Normalmente, os alimentos envolvidos nos surtos são água e gelo, alimentos crus e prontos para consumo [23]. A dose infectiva presumida é de 10 - 100 partículas virais. A técnica de ELISA vem sendo a mais utilizada no diagnóstico através da detecção das partículas virais nos espécimes clínicos. O isolamento do vírus a partir de qualquer alimento não tem sido associado a surtos e nenhum método eficiente está disponivel para análise rotineira de alimentos. No entanto, os ensaios para detecção do vírus em água ou espécimes clínicos podem ser adaptados a este propósito, tais como ELISA, sondas genéticas e amplificação em cadeia de reação de polimerase [11].

Segundo CIARLET \& ESTES [7], a infecção por rotavirus responde por $45 \%$ das doenças diarréicas graves em crianças em todo o mundo. Em países subdesenvolvidos, estima-se que 600.000 mortes ocorram anualmente em função desta infecção.

Além de ser veiculado diretamente através de alimentos, o rotavírus tem-se mostrado viável em superfícies inanimadas, como metais, vidros e plásticos por mais de 10 dias em temperatura ambiente [16].

Os rotavírus infectam enterócitos das microvilosidades do intestino delgado, onde multiplicam-se, no citoplasma, causando danos ao seu mecanismo de transporte [15]. Em pesquisas recentemente realizadas, veri- 
ficou-se que a patogenicidade do rotavirus é multifatorial, e a capacidade deste vírus induzir à secreção de fluido intestinal é atribuída, em parte, à produção da enterotoxina "NSP4", a qual é responsável por lesões teciduais observadas em animais modelos.

A toxina NSP4 é suspeita de iniciar o processo diarréico secretório, através da ativação do sistema nervoso entérico, colaborando indiretamente na síntese de outros compostos biologicamente ativos (mediadores) ou neurotransmissores em células inflamatórias ou endócrinas do intestino [7].

Os vírus causadores de gastroenterite podem ser veiculados por água e alimentos, sendo sua veiculação passiva, uma vez que os mesmos somente se multiplicam quando dentro de uma célula viva. Os vírus considerados patogênicos têm veiculação oro-fecal, mediada ou não por alimentos. Quando em alimentos, esses vírus podem ser inativados biologicamente por temperaturas elevadas, condições especiais de $\mathrm{pH}$ e umidade [15]. MAHONY et al. [16] demonstraram que o rotavírus é relativamente sensível ao calor e que o cozimento e o reaquecimento de alimentos potencialmente contaminados são suficientes para destruir a infectividade do vírus contaminante. Além disso, também foi demonstrado por estes autores que o rotavirus é relativamente estável em baixo $\mathrm{pH}$, podendo sobreviver em temperaturas de refrigeração, apresentando-se viável em contaminação experimental em suco de frutas.

De acordo com a Organização Mundial de Saúde (OMS), uma a cada três pessoas, em países industrializados, são afetadas por doenças veiculadas por alimentos anualmente, resultando em sofrimento humano e em perdas econômicas que giram em torno de alguns bilhões de dólares. A OMS [27] e a Organização das Nações Unidas para Agricultura e Alimentação (FAO) afirmam que um alimento seguro significa um menor número de casos de doenças alimentares, menores custos na saúde pública, menos barreiras ao comércio internacional, menos perdas e melhor produtividade [19].

Desse modo, as questões relacionadas com a segurança alimentar constituem indiscutivelmente, no momento atual, uma preocupação de ordem geral, abrangendo entidades oficiais, agentes econômicos e consumidores. A adoção de técnicas que permitam maior segurança na manipulação dos alimentos vem sendo objeto de diversos grupos de pesquisa em todo o mundo [20, 21, 24, 25].

Segundo a Resolução RDC no 12 , que aprova o Regulamento Técnico sobre Padrões Microbiológicos para Alimentos, o alimento é considerado impróprio para consumo humano quando apresentar condições sanitárias insatisfatórias, cujos resultados analíticos demonstram a presença ou a quantificação de microrganismos patogênicos ou toxinas que representem risco à saúde do consumidor. Uma vez que não existe legislação específica para os vírus envolvidos em doenças transmitidas por alimentos, estabelecendo limites máximos aceitáveis, a detecção destes no alimento, torna-o impróprio para consumo.
Como forma preventiva, a Portaria CVS-6 / 99 de 10.03.99 estabelece os critérios de higiene e de boas práticas operacionais para alimentos produzidos/ fabricados / industrializados / manipulados e prontos para o consumo, aplicando-se a todos os estabelecimentos nos quais sejam realizadas algumas das seguintes atividades: produção, industrialização, fracionamento, armazenamento e transporte de alimentos. Ainda, a Portaria no 326 - SVS / MS, de 30 de julho de 1997 obriga que tais estabelecimentos tomem providências para que todas as pessoas que manipulem alimentos recebam instrução adequada e contínua em matéria higiênico-sanitária, na manipulação dos alimentos e higiene pessoal, com vistas a adotar as precauções necessárias para evitar a contaminação dos alimentos. Tal capacitação deve abranger situação de saúde do manipulador, enfermidades contagiosas, feridas, lavagem de mãos e higiene pessoal [2].

O presente trabalho relata um surto de gastroenterite atribuído ao rotavírus em uma empresa que oferecia refeições rápidas (lanches) aos seus funcionários.

\section{2 - MATERIAL E MÉTODOS}

Em estabelecimento comercial localizado na cidade do Rio de Janeiro, Brasil, 51 pessoas dentre os 720 funcionários relataram sintomas de mal-estar, vômito, diarréia, náusea e calafrios, sendo encaminhadas ao atendimento médico e submetidas a análises hematológicas. Os funcionários da empresa foram submetidos à pesquisa epidemiológica, utilizando formulários, questionando quanto ao consumo de alimentos oferecidos ou não no local de trabalho, horário de consumo, apresentação dos sintomas e horário do início dos sintomas.

No dia seguinte ao início dos sintomas, foi realizada análise microbiológica da água, coletada em diversos pontos, bem como de todos os alimentos e bebidas oferecidos para consumo, a saber: chá-mate, leite, manteiga, requeijão e pão. Os funcionários presentes responsáveis pela manipulação dos alimentos servidos foram avaliados quanto ao processo de higienização das mãos, em exame realizado com auxílio de swabs.

\section{1 - Pesquisa de Salmonella}

Para esta análise foi utilizada a metodologia preconizada por POPPE \& MANN [22] constituída de quatro etapas: pré-enriquecimento, enriquecimento seletivo, plaqueamento diferencial e sorologia. O resultado desta análise indica apenas ausência ou presença em $25 \mathrm{~g}(\mathrm{~mL})$ de amostra. Sendo o caso positivo, o alimento em questão é considerado impróprio para consumo. Os meios de cultura utilizados foram: água peptonada tamponada, caldo selenito cistina, caldo tetrationato, ágar SS (Salmonella/ Shiguella), ágar Rambach, ágar tríplice açúcar ferro (TSI), ágar lisina ferro (LIA), soro polivalente. Para a execução foram procedidas as seguintes etapas:

- Pré-enriquecimento: pesaram-se, assepticamente, $25 \mathrm{~g}$ de amostra em erlenmeyer previamente esterilizado e adicionaram-se $225 \mathrm{~mL}$ de água peptonada 
tamponada, deixando por 24 horas em estufa a 35$37^{\circ} \mathrm{C}$.

- Enriquecimento seletivo: após incubação, transferiram-se alíquotas de $1 \mathrm{~mL}$ do caldo de pré-enriquecimento para 2 tubos contendo $10 \mathrm{~mL}$ caldo selenito cistina e $10 \mathrm{~mL}$ de caldo tetrationato, respectivamente, incubando-se novamente por 24 horas em estufa a $35-37^{\circ} \mathrm{C}$.

- Plaqueamento diferencial: a partir de cada tubo incubado, com auxílio de alça de platina foram feitas estrias do material em placas contendo ágar Rambach e ágar SS. Incubou-se em estufa a $35-37^{\circ} \mathrm{C}$ por 24 horas.

\section{2 - Contagem de bactérias aeróbias mesófilas}

Foram pesadas assepticamente $10 \mathrm{~g}$ de amostra e diluídas em $90 \mathrm{~mL}$ de água peptonada, homogeneizando-se em "stomacher" (diluição $10^{-1}$ ). As semeaduras foram feitas em duplicata, em placa de Petri estéreis: semeou-se $1 \mathrm{~mL}$ da diluição e, em seguida, verteu-se o meio ágar padrão para contagem (Plate Count), a aproximadamente $45^{\circ} \mathrm{C}$, cobrindo toda superfície da placa (método pourplate). Incubou-se em estufa regulada a $32^{\circ} \mathrm{C}$ por 48 horas [9, 13].

\section{3 - Contagem de Bacillus cereus}

Seguindo a metodologia descrita por AGATA, OHTA \& YOKOYAMA [1], 10g de amostra foram pesadas assepticamente e diluídas em $90 \mathrm{~mL}$ de água peptonada, homogeneizando-se em "stomacher" (diluição 10-1). Os meios de cultura utilizados foram: ágar seletivo para Bacillus cereus (Oxoid $\AA$ ), gema de ovo (Oxoid $®$ ), soro específico (Oxoid( $\left.{ }^{\circledR}\right)$. Foi semeado em superfície de placas contendo ágar seletivo para Bacillus cereus, $0,1 \mathrm{~mL}$ da diluição escolhida. Este material foi incubado em estufa a $35-37^{\circ} \mathrm{C}$ por 48 horas.

\section{4 - Contagem de estafilococos coagulase-positivos}

A técnica para esta análise está relacionada à capacidade deste microrganismo de reduzir telurito de potássio a telureto, fazendo com que as colônias apresentem coloração negra, e hidrolizar a gema de ovo, produzindo um halo em torno da colônia. Foram pesadas assepticamente $10 \mathrm{~g}$ de amostra e diluídas em $90 \mathrm{~mL}$ de água peptonada, homogeneizando-se em "stomacher" (diluição $10^{-1}$ ). As semeaduras foram feitas em duplicata. Foi semeado $0,1 \mathrm{~mL}$ da solução matriz em placas contendo ágar Baird Parker enriquecido com gema de ovo com telurito, que foi incubado por 48 horas em estufa a 35 $37^{\circ} \mathrm{C}[13,17]$.

\section{5 - Determinação de coliformes fecais (Escherichia coli)}

As bactérias do grupo coliforme são capazes de fermentar lactose. Nesta análise, o gás produzido a partir da fermentação fica retido em tubo de Durham, formando uma "bolha" de ar dentro do mesmo. Quanto à presença de Escherichia coli, verifica-se através da fluores- cência do caldo frente à luz ultravioleta, em ambiente escuro. A fluorescência é resultante da degradação de uma substância presente no meio, MUG (emetilumbeliferil- $\beta$-D-glicurônídeo), pela enzima $\beta$ glicuronidase, produzida por aproximadamente $96 \%$ das cepas de Escherichia coli. Pesaram-se assepticamente $10 \mathrm{~g}$ de amostra e executou-se diluição com $90 \mathrm{~mL}$ de água peptonada, homogeneizando-se em "stomacher" (diluição $10^{-1}$ ). Os plaqueamentos foram feitos em duplicata e as placas foram incubadas invertidas. Semeou-se $1 \mathrm{~mL}$ da solução matriz em três tubos contendo caldo Lauril Sulfato Fluorocult e tubos de Durham. Repetiu-se este procedimento com diluições $10^{-2}$ e $10^{-3}$ (ou diluições maiores, de acordo com estimativa inicial de contaminação). Incubou-se este material em estufa controlada a $35-37^{\circ} \mathrm{c}$ por 48 horas (KONEMAN, 2001).

\section{6 - Contagem de clostrídio sulfito redutor a $46^{\circ} \mathrm{C}$}

Este microrganismo é capaz de reduzir sulfito a sulfeto. Sendo assim, utilizou-se meio rico em sulfito para enumeração deste, onde as colônias características apresentam coloração negra, em virtude deste processo de redução. Foram pesadas assepticamente $10 \mathrm{~g}$ de amostra e diluídas em $90 \mathrm{~mL}$ de água peptonada, homogeneizando-se em "stomacher" (diluição 10 ${ }^{-1}$ ). Foi inoculado $0,1 \mathrm{~mL}$ da solução matriz em profundidade em tubo contendo ágar SPS e, imediatamente após, colocou-se o tubo em banho de gelo. O banho de gelo tem como objetivo acelerar a solidificação do meio, promovendo a anaerobiose no mesmo e não permitir que a amostra migre para a superfície. Em seguida, incubouse em estufa regulada a $45-46^{\circ} \mathrm{C}$ por $24-48$ horas [13].

\section{7 - Avaliação das condições higiênicas dos mani- puladores}

A avaliação das condições de higiene das mãos dos manipuladores, com auxílio de swabs, pesquisando-se a presença dos patógenos Escherichia colie Staphylococos aureus, além da contagem total de aeróbios mesófilos. Foram feitos esfregaços em aproximadamente $5 \mathrm{~cm}^{2} \mathrm{de}$ pele utilizando swab estéril embebido em água peptonada, também estéril. Cada $s w a b$ foi guardado separadamente em tubos de ensaio, contendo $5 \mathrm{~mL}$ de água peptonada e transportado, sob refrigeração até o laboratório. Foi semeado $0,1 \mathrm{~mL}$ desta água peptonada em três placas contendo, cada uma, os meios de cultura Ágar Padrão para Contagem (PCA), Eosina-Azul de Metileno (EMB) e Baird Parker. As placas contendo EMB e Baird Parker foram incubadas a $35-37^{\circ} \mathrm{C}$ por $24-48$ horas e as placas com PCA foram incubadas durante o mesmo tempo, porém a $32^{\circ} \mathrm{C}$. Após a identificação presuntiva das colônias, de acordo com suas características de crescimento, estabeleceu-se metodologia de identificação pertinente ao microrganismo suspeito [20, 24].

\section{8 - Estimativa do risco atribuivel}

A estimativa do risco atribuivel a cada alimento foi efetuada através do cálculo da taxa de ataque específica entre os que consumiram dado alimento, subtraída da 
taxa de ataque específica entre os que não consumiram, apontando como alimento suspeito aquele que apresenta o maior valor $[10,12]$.

A taxa de ataque é calculada da seguinte maneira:

$\mathrm{TA}=100 \mathrm{D} /(\mathrm{D}+\mathrm{ND}) \mathrm{X} 100$ (onde D é "doente" e ND é "não doente").

\section{3 - RESULTADOS E DISCUSSÃO}

A análise da água não denunciou qualquer indicativo de contaminação microbiana. Os alimentos e bebidas apresentavam-se dentro dos padrões legais vigentes, notando-se, porém, que o prazo de validade da manteiga servida havia expirado. À exceção de um dos manipuladores de alimentos, apresentando carga microbiana elevada de Staphylococcus aureus nas mãos, os demais presentes no dia da análise, responsáveis pela manipulação dos alimentos servidos, demonstraram eficiência no processo de higienização das mãos. As Tabelas 1 e 2 foram compiladas a partir dos dados coletados na entrevista realizada com os funcionários.

TABELA 1. Relação de pessoas que consumiram os alimentos dispostos na tabela

\begin{tabular}{lcccc}
\hline & DOENTES & NÃO DOENTES & TOTAL & DOENTES (\%) \\
\hline CHÁ-MATE & 2 & 11 & 13 & 15,4 \\
PÃO COM MANTEIGA & 9 & 14 & 23 & 39 \\
AGUA & 7 & 9 & 16 & 44 \\
CAFÉ COM LEITE & 3 & 2 & 5 & 60 \\
ACHOCOLATADO & 4 & 6 & 10 & 40 \\
\hline
\end{tabular}

TABELA 2. Relação de pessoas que não consumiram os alimentos dispostos na tabela

\begin{tabular}{lcccc}
\hline & DOENTES & NÃO DOENTES & TOTAL & DOENTES (\%) \\
\hline \hline CHÁ-MATE & 7 & 10 & 17 & 41,17 \\
PÃO COM MANTEIGA & 0 & 7 & 7 & 0 \\
ÁGUA & 2 & 12 & 14 & 14,2 \\
CAFÉ COM LEITE & 6 & 19 & 25 & 24 \\
ACHOCOLATADO & 5 & 15 & 20 & 25 \\
\hline
\end{tabular}

Risco atribuível dos alimentos:

1. Chá-mate: $-25,77 \%$

2. Pão com manteiga: $39,0 \%$

3. Água: $29,8 \%$

4. Café com leite: $36,0 \%$

Os resultados das Tabelas 1 e 2, dispostas acima, determinam o risco atribuível em função do número de indivíduos que consumiram todos os alimentos avaliados e manifestaram ou não sintomatologia clínica de gastroenterite.

Os alimentos não apresentaram contaminações por microbiota bacteriana patogênica, nem apresentavam alterações em suas características sensoriais. Em virtude da deficiência de dados que apontassem o motivo do surto, foram confeccionadas as Tabelas 1 e 2, com o objetivo de se cruzar informações e apontar algum alimento ou bebida suspeito de causar ou veicular alguma doença de origem alimentar. Analisando-se as Tabelas 1 e 2, foi verificado que $100 \%$ dos indivíduos que apresentaram sintomatologia consumiram pão com manteiga, acu- sando este alimento como principal suspeito de veiculação da doença. Isto é confirmado pelo cálculo do risco atribuível de cada um dos alimentos, onde a taxa de ataque específica entre os que consumiram dado alimento, subtraída da taxa de ataque específica entre os que não consumiram tal alimento, aponta como alimento suspeito, aquele que apresenta o maior valor [10]. Paralelamente a isto, constatou-se na entrevista com os manipuladores a ausência de um deles, o qual encontrava-se afastado temporariamente de suas funções por motivos de saúde, relatando que apresentava sintomatologia gastrointestinal semelhante a das pessoas acometidas. Tal manipulador teria sido responsável pelo preparo dos pães com manteiga em data próxima a da ocorrência do surto. As 51 pessoas hospitalizadas receberam o diagnóstico clínico-laboratorial de infecção por rotavírus. Desta forma, percebe-se que houve falhas na manipulação, permitindo contaminação por rotavírus, cuja principal importância reside no fato de que este é veiculado sem comprometer as características sensoriais e organolépticas do produto. Isto alerta para o fato de que as infecções por agentes virais podem ser subestimadas em sua importância clínica e epidemiológica no que concerne a doenças alimentares. Numa investigação mais apurada dos manipuladores envolvidos, verificou-se a infecção do manipulador incumbido no preparo dos pães com manteiga, sendo diagnosticada em laboratório especializado, como por vírus entérico. Desse modo, considera-se que esta pessoa tenha sido responsável pela veiculação deste agente aos consumidores do produto tido como suspeito, uma vez que segundo relatos de funcionários, tal manipulador preparou estes pães já apresentando os sintomas descritos e, em seguida, foi afastado temporariamente do serviço para cuidados médicos. Pessoas infectadas por vírus que apresentam tropismo pelo trato gastroentérico, podem contaminar alimentos prontos para consumo quando os manipulam em condições higiênicas insatisfatórias [21].

A avaliação das condições de higiene dos manipuladores visa o controle da higiene de mãos/luvas de profissionais que manipulam diretamente os alimentos. A presença de microrganismos, em elevada concentração, na superfície das mãos indica ineficiência nos procedimentos de antissepsia ou contaminação no contato com outras superfícies, o que acarretaria contaminação para o alimento em questão e conseqüente interferência na segurança do mesmo. No que diz respeito à veiculação do vírus indicado neste relato de caso, como medidas preventivas, seria necessário garantir que os manipuladores de alimentos praticassem boa higiene pessoal, controle de saúde, lavagem e sanitização de utensílios, equipamentos e outras superfícies inanimadas. Outras medidas de controle são importantes para promover a segurança geral dos alimentos: cozimento dos alimentos em temperaturas internas mínimas de segurança e uso de água limpa e clorada [25]. Dentro da necessidade de estabelecer adequada higiene na manipulação de alimentos, o procedimento para lavagem das mãos preconizado pela Agência Nacional de Vigilância Sanitária (ANVISA) é descrito a seguir, de forma detalhada: 
- Abrir a torneira, regulando a água para um jato constante e com temperatura agradável, e molhar as mãos; colocar mais ou menos 2 a $5 \mathrm{~mL}$ de sabão líquido nas mãos ou friccionar as mãos com sabão em barra;

- Friccionar as palmas e espaços interdigitais, esfregar a palma da mão direita sobre o dorso da mão esquerda e vice-versa, esfregar o polegar direito com a mão esquerda e vice-versa;

- Fazer movimentos circulares com as pontas dos dedos da mão direita unidos sobre a palma da mão esquerda fechada em concha, e vice-versa;

- Esfregar com a palma da mão esquerda em concha sobre a mão direita fechada, em movimentos de vai-e-vem e vice-versa e esfregar o punho com movimentos circulares;

- Enxaguar as mãos retirando totalmente os resíduos de sabão e secar cuidadosamente, iniciando pelas mãos e seguindo pelos punhos e cotovelos com papel-toalha descartável;

- Utilizar torneira que dispense o contato de mãos contaminadas através do seu volante, quando do fechamento da água ou utilizar a toalha de papel para fechar a torneira;

- Desprezar o papel no cesto de lixo.

- Este procedimento requer, em média, 15 a 30 segundos.

\section{4 - CONCLUSÕES}

Os alimentos não apresentaram contaminações por microbiota bacteriana patogênica, nem apresentavam alterações em suas características sensoriais. Sendo verificado que $100 \%$ dos indivíduos que apresentaram sintomatologia consumiram pão com manteiga, considerando-se este alimento como principal suspeito de veiculação da doença, confirmado pelo cálculo do risco atribuível de cada um dos alimentos. Um dos manipuladores encontrava-se afastado temporariamente de suas funções por motivos de saúde, relatando que apresentava sintomatologia gastrointestinal semelhante à das pessoas acometidas, tendo sido responsável pelo preparo dos pães com manteiga em data próxima à da ocorrência do surto. Desta forma, percebe-se que houve falhas na manipulação, permitindo contaminação por rotavírus, cuja principal importância reside no fato de que este é veiculado sem comprometer as características sensoriais e organolépticas do produto. Isto alerta para o fato de que as infecções por agentes virais podem ser subestimadas em sua importância clínica e epidemiológica no que concerne a doenças alimentares.

\section{5 - REFERÊNCIAS BIBLIOGRÁFICAS}

[1] AGATA, N.; OHTA, M.; YOKOYAMA, K.. Production of Bacillus cereus emetic toxin (cereude) in various foods. International Journal at Food Microbiology.v.73, p. 23-27. 2002.
[2] BILLY, T.J. HACCP - a work in progress. Food Control, v. 13, n.6-7, p. $359-362,2001$.

[3] BRYAN, F. L., JERMINI, M., SCHMITT, R., CHILUFYA, E. N., MWANZA, M.,MATOBA, A., MFUME, E., \& CHIBIYA, H. Hazards associated with holding and reheating foods at vending sites in a small town in Zambia. Journal of Food Protection, v. 60, p. 391-398, 1997.

[4] BRYAN, F. L., TEUFEL, P., RIAZ, S., ROOHI, S., QADAR, F., \& MALIK, $Z$. Hazards and critical control points of vending operations at a railway station and bus station in Pakistan. Journal of Food Protection, v. 55, p. 534-541, 1992a.

[5] BRYAN, F. L., TEUFEL, P., RIAZ, S., ROOHI, S., GADAR, F., \& MALIK, Z.. Hazards and critical control points of streetvending operations in a mountain resort town in Pakistan. Journal of Food Protection, v. 55, p. 701-707, 1992b.

[6] BRYAN, F. L., TEUFEL, P., RIAZ, S., ROOHI, S., QADAR, F., \& MALIK, Z. Hazards and critical control points of streetvended chat, a regionally popular food in Pakistan. Journal of Food Protection, v. 55, p. 708-713, 1992c..

[7] CIARLET, M. \& ESTES, M. K. Interations between rotavirus and gastrointestinal cells. Current Opinion Microbiology, v. 4 , n. 4, p.435-441, 2001.

[8] FIRST PAN-EUROPEAN CONFERENCE ON FOOD QUALITY AND SAFETY. Foodborne Diseases are on the Rise In Europe - Fao/Who Call For Better Consumer Protection. Press Release WHO/10. 25 th February, 2002

[9] GAVA, A. J. Princípios de Tecnologia de Alimentos. Editora Nobel, São Paulo, 1998.

[10] GUIAVETA - Guia de Sistema de Vigilância das Enfermidades Transmitidas por Alimentos (VETA) e a Investigação de Surtos, 2001.

[11] GLASS R.I., KILGORE P.E., HOLMAN R.C.. The epidemiology of rotavirus diarrhea in the United States: surveillance and estimates of disease burden. Journal of Infectious Diseases, v. 174, p. S5-S11, 1996.

[12] HOORNSTRA, E., NORTHOLT, M.D., NOTERMANS, S., \& BARENDSZ, A. W. The use of quantitative risk assessment in HACCP. Food Control, v. 12, n. 4, p. 229-234, 2001.

[13] HYGIENE ALIMENTAIRE - Textes Généraux - Méthodes Générales dánalyse bactériologique. Journal Officiel de la Reublique Française, no 1488 - Annexe II, p. 115-119, 1982.

[14] INSTITUTO DE HOSPITALIDADE - Serv Safe Princípios Básicos de Segurança Alimentar, 2000.

[15] JAWETZ, E., MELNICK, J. L., ADELBERG, E. A., BROOKS, G. F., BUTEL, J. S. \& ORNSTON, L.N. 2001.Microbiologia Médica. Guanabara-Koogan, Brasil.

[16] KONEMAN, E.W.; ALLEN, S.D.; JANDA, W.M. \& SCHRECKENBERGER, P.C. \& WINN JR., W.C. Diagnóstico Microbiológico. 5.ed. Rio de Janeiro: Editora MEDSI, 2001, 1465 p.

[17] MAHONY, J. O, DONOGHUE, M. O, MORGAN, J. G., HILL, C. Rotavirus survival and stability in foods as determined by na optimised plaque assay procedure, Internatinal Journal of Microbiology. v. 61, p. 177-185, 2000.

[18] MINISTÉRIO DO ABASTECIMENTO E DA REFORMA AGRÁRIA, SECRETARIA DE DEFESA AGROPECUÁRIA, DEPARTAMENTO DE DEFESA ANIMAL, COORDENAÇÃO GERAL DE LABORATÓRIO ANIMAL. Métodos de análise microbiológica para alimentos. 1991/1992-2 ${ }^{a}$ revisão.

[19] MOSUPYE, F. M., \& VON HOLY, A. Microbiological quality and safety of street-vended foods in Johannesburg city, South Africa. Journal of Food Protection, v. 62, p. 12781284, 1999. 
[20] MOTARJEMI, Y. \& KAFERSTEIN, F.K. Global estimation of foodborne diseases. World Health Statistics Quarterly, v. 50, n. 1-2, p. 5-11, 1997.

[21] PANISELLO, P.J. \& QUANTICK, P.C. Technical barriers to Hazard Analysis Critical Control Point (HACCP). Food Control, v. 12, n. 3, p. 165-173, 2001.

[22] PANISELLO, P.J., ROONEY, R., BUANTICK, P. \& STANWELL-SMITH, R. Application of foodborne disease outbreak data in the development and maintenance of HACCP systems. International Journal of Food Microbiology, v. 59, n. 3, p. 221-234, 2000.

[23] POPPE, C.; MANN, E. D.. 1998. Méthode d'isolement des espèces du genre salmonella sur milieu modifié semi-solide de rappaport-vassiliadis (msrv). Procédure de laboratoire MFLP-75, Canadá.

[24] SCHOFIELD GM. Emerging foodborne pathogens and their significance in chilled foods. Journal of Applied Bacteriology, v. 72, p. 267-73, 1992.
[25] SENAC DN - Elementos de Apoio, Boas Práticas e Sistema de APPCC, 2001.

[26] SRIANO, J.M., RICO, H., MOLTÓ, J. C., \& MAÑES, J. Effects of introdution of HACCP on the microbiology quality of some restaurant meals. Food Control, v. 13, n. 4-5, p. 253$261,2002$.

[27] TAUXE, R. V. Suveillance and investigation of foodborne diseases; roles for public health in meeting objectives for food safety. Food Control, v. 13, n. 6-7, pp. 363-369, 2002.

[28] WHO Fact Sheet No. 124. 1996. Emerging Foodborne Diseases

\section{6 - AGRADECIMENTOS}

À empresa Bioqualitas Análises de Alimentos e Treinamentos Contínuos Ltda. que suportou o desenvolvimento deste trabalho. 